\title{
Estratégia de representação em projeto de logotipia: Leitura semiótica da marca gráfica UNO/FIAT
}

\author{
Strategy representation in logo design: Semiotic reading of the graphic brand UNO / FIAT
}

\author{
CAMPOS, Bruno; Especialista; \\ Universidade Federal de Santa Catarina - UFSC \\ bruno12design@hotmail.com \\ PERASSI, Richard; Doutor; \\ Universidade Federal de Santa Catarina - UFSC \\ richard.perassi@uol.com.br
}

\begin{abstract}
RESUMO
No ano de 2010, houve o lançamento da nova linha de automóveis da marca "Uno", informalmente denominada como "Novo Uno", fabricados pela montadora "Fiat", cuja publicidade propõe o slogan "Novo Uno. Novo Tudo". O objetivo do presente artigo é verificar a relação visual existente entre o logotipo UNO, principal objeto de estudo do trabalho, com o automóvel UNO. A teoria Semiótica, primeiramente proposta por Charles Peirce, é aqui adotada para a interpretação do processo de representação do logotipo. Com base em uma metodologia descritiva, a ideia defendida neste texto considera que houve uma dupla estratégia de associação do logotipo aos novos automóveis da marca "Uno". Essa estratégia é baseada em convenção simbólico-arbitrária e, também, em semelhança ou analogia entre as sensações e as significações, que são propostas pela visualidade dos automóveis e pela visualidade do logotipo.
\end{abstract}

Palavras-chave: Gestão de Design. Marca de Automóvel. Identidade Gráfico-Visual

\begin{abstract}
In 2010, there was the launch of the new line of cars brand "Uno", informally known as "Novo Uno", manufactured by the automaker "Fiat", which proposes the advertising slogan "Novo Uno. Novo Tudo". The objective of this paper is to investigate the visual relationship between UNO logo, the main object of study of this work, with the car UNO. The Semiotics theory, first proposed by Charles Peirce, is adopted here to interpret the process of representation of the logo. Based on a descriptive analysis, the idea defended in this paper considers that there was a dual strategy of association of logo with the brand new cars "Uno." This strategy is based on symbolic and arbitrary convention, and also in the likeness or analogy between the sensations and meanings, which are proposed by the visuality of the cars and by visuality of the logo.
\end{abstract}

Keywords: Design Management. Automobile Manufacturer. Visual-Graphic Identity

\section{Apresentação}

Este artigo é produto de estudos e pesquisa desenvolvidos durante o curso de especialização em Gestão de Design promovido pelo Núcleo de Gestão de Design (NGD/UFSC), através do Programa de Pós-graduação em Design e Expressão Gráfica (Pós-Design/EGR/UFSC).

Apresenta-se aqui uma leitura semiótica do logotipo da marca "Uno" que, recentemente, 
passou a identificar um novo modelo de automóvel, que foi lançado no ano de 2010, endossado pela marca italiana "Fiat", que também representa uma montadora brasileira de veículos.

Atualmente, as marcas gráficas de organizações e produtos globais compõem e participam da visualidade urbana em todo o mundo, afetando públicos diversificados com diferentes culturas, religiões, condições sociais ou econômicas.

Tradicionalmente, uma marca gráfica é representada por um logotipo, como a imagem de nome da marca grafado de maneira particularizada, ou por um símbolo gráfico-figurativo, que também é apresentado como imagem representativa da marca. Assim, a marca gráfica pode ser um logotipo ou um símbolo, Mas, geralmente, é composta pelo conjunto de um logotipo e um símbolo. Quando apresentado como marca de organização ou produto, o conjunto com os dois elementos ou apenas um elemento isolado são denominados como "marca gráfica", "assinatura visual" ou simplesmente "logo",

No contexto da área de Design Gráfico, o projeto de um signo ou um conjunto de signos para representar uma marca é desenvolvido como a parte central do trabalho de projetação da identidade gráfico-visual da marca.

A marca gráfica, como um logotipo, um símbolo figurativo ou ambos é, portanto, resultado de um processo de criação bem planejado e direcionado a objetivos específicos que são: (1) servir de elemento de identificação e distinção da marca; (2) servir como atestado de origem dos produtos e serviços de um fornecedor, e (3) apresentar-se como síntese dos valores da marca, do produto ou serviço que representa.

De maneira geral, a temática proposta pelo significado do nome ou pela imagem do símbolo é relacionada aos valores da marca. Mas, além disso, o formato, as cores e outros aspectos expressivos do logotipo e do símbolo, também, expressam e representam, de maneira intencional ou acidental, os valores da marca.

Como em todo conjunto de signos, a potencialidade significativa do conjunto de elementos visuais, que compõem o logotipo, o símbolo ou o conjunto desses, é mais ampla do que as pensadas e previstas pelos emissores da marca. Assim, pode-se perguntar aos emissores e ao designer projetista da marca o que a marca representa. Todavia, a significação de um logotipo ou de outro símbolo visual é sempre mais ampla que o previsto, justificando um estudo interpretativo da marca de acordo com a cultura em que é percebida.

A pesquisa realizada se caracteriza como "Descritiva", porque "observa, registra, correlaciona e descreve fatos ou fenômenos de uma determinada realidade sem manipulá-los" (VALETIM, 2005). Para o desenvolvimento da pesquisa, foram realizadas as seguintes etapas: (1) estudos exploratórios; (2) estudos teóricos e (3) pesquisa documental. Assim, foram realizados: (1) levantamento do material de estudo; (2) revisão teórica, e (3) coleta de imagens e outros dados na internet.

Os estudos teóricos consideraram especialmente a teoria Semiótica, que foi primeiramente proposta por Charles Sanders Peirce (1839-1914). Assim, essa é a principal matriz teórica utilizada na interpretação do logotipo "Uno", que é a marca gráfica em estudo.

\section{Apontamentos sobre a Marca "Uno"}

As informações a seguir foram pesquisadas na internet, no sítio da revista Quatro Rodas (2010) e tratam do processo de identificação de diferentes modelos de automóveis com a utilização do nome "Uno" endossado pela marca italiana "Fiat". O logotipo ou marca gráfica do nome, também, passou por transformações durante esse processo.

A marca "Fiat" fez o lançamento do automóvel "Uno" (Fig. 1), em 1983, e sua comercialização aconteceu a partir do ano de 1984, como o primeiro carro mundial da montadora. O modelo "uno" substituiu o já veterano "Fiat 127" que, no Brasil, serviu de base para o conhecido modelo "Fiat 147". 


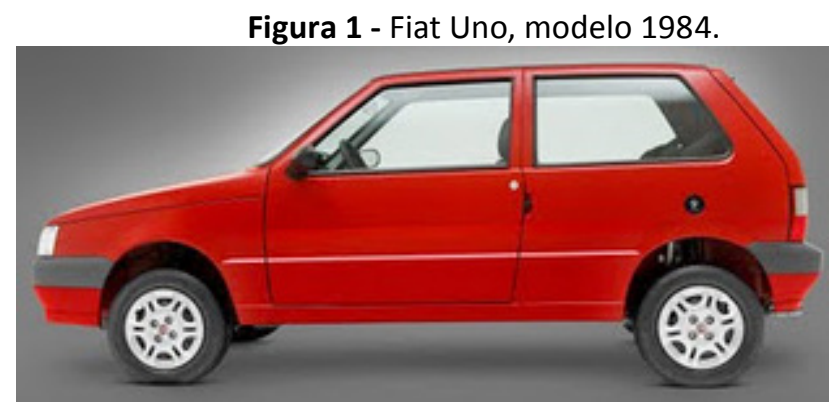

Fonte: Blog Fiat Fictícia (2011).

O projeto inicial foi do designer italiano Giorgetto Giugiaro. Exteriormente, o automóvel apresentava linhas retas e angulosas, com detalhes inovadores, como as maçanetas embutidas na versão de duas portas. Assim, o modelo foi percebido de maneira diferenciada com relação aos concorrentes.

A preocupação com ergonomia e funcionalidade era notada no desenho interior do carro. Por exemplo, os comandos foram considerados de fácil acesso, porque eram situados bem próximos ao volante. Além disso, o espaço interno era privilegiado, já que o teto elevado aumentava a sensação de amplitude.

Em 1984, o lançamento do carro no Brasil dividiu opiniões e seu desenho diferenciado, com formas retilíneas, não foi imediatamente aprovado pelo gosto do público consumidor. Entretanto, posteriormente, automóveis da marca "Uno" tornaram-se populares entre os brasileiros, sendo que essa condição foi consolidada na década de 1990. A versão "Uno Mille" inaugurou o segmento de automóveis populares no Brasil e, historicamente, é a marca com maior número de vendas de carro "zero quilômetro" neste país.

O sucesso da versão "Uno Mille" foi seguido com o lançamento do modelo "Mille Turbo", como o primeiro carro "turbo" de fabricação em série no Brasil, ocupando o lugar no mercado do modelo "Uno 1.6 R". De maneira diferente do modelo "Uno Mille", os modelos "Uno 1.6 R" e "Uno Turbo" foram os mais procurados por consumidores mais jovens, devido a maior potência de motor das duas versões.

O modelo "Uno Mille" permaneceu no mercado até o ano de 2009, resistindo como um produto de forte apelo popular, devido ao bom desempenho e ao preço acessível. Pois, mantevese com o preço mais atraente no mercado nacional, diante dos modelos populares das montadoras concorrentes.

A ênfase nos aspectos objetivos, funcionais e econômicos, foi evidenciada com a versão "Economy", que apresenta no painel um aparelho denominado "econômetro", para indicar se o modo do motorista conduzir o veículo prioriza a economia de combustível. Todavia, o desgaste estéticosimbólico do modelo "Uno Mille" foi sendo percebido, a despeito das versões diferenciadas do produto. Isso foi indicado na versão "Way", cujos detalhes de acabamento permitem que o automóvel seja percebido com um estilo definido como "esportivo-urbano".

Em maio de 2010, o lançamento do novo modelo "Uno" confirmou que houve a percepção da necessidade de atualização estilística do automóvel. Porém, o modo como o novo modelo "Uno" (Fig. 2) foi apresentado e introduzido no mercado indicou o cuidado da montadora "Fiat", para não perder o posicionamento conquistado pelo antigo modelo "Uno Mille". 
Figura 2 - Fiat Uno, versão “Way”, modelo 2011.

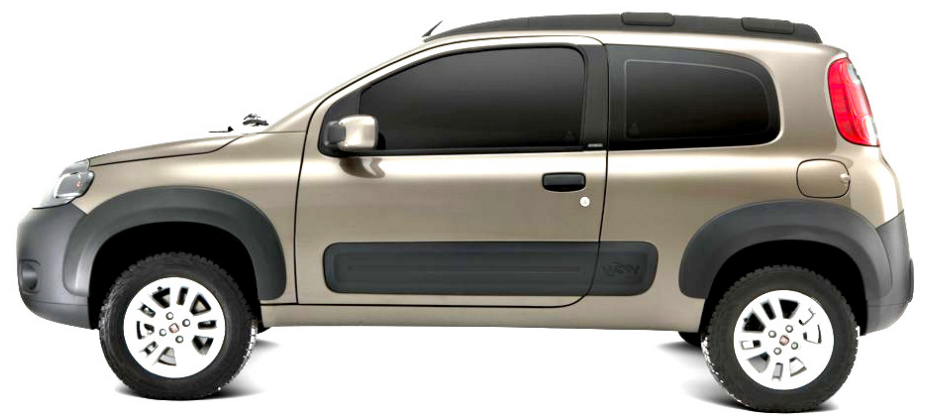

Fonte: Sítio Revista Mecânica On Line (2011)

O modelo de automóvel "Mille" foi mantido desde 2010, inclusive na versão "Way" (Fig. 2), sendo que o automóvel já é oferecido na versão 2012. Porém, foi retirado o nome "Uno", que passou a identificar o novo modelo. Primeiramente, o novo modelo "Uno" foi lançado e vendido na versão de quatro portas laterais. Somente no final do mês de fevereiro de 2011, depois de confirmada a aceitação do novo modelo pelo público consumidor, foi apresentada e passou a ser comercializada a versão de duas portas do novo modelo "Uno", com o lançamento do modelo para o ano de 2012.

A comercialização do novo modelo "Uno" com duas portas laterais é uma indicação da saída do modelo "Mille" do mercado, porque será definitivamente substituído. Todavia, considera-se que ainda há necessidade de adaptações para que o novo modelo possa ser comercializado com preço equivalente ao modelo anterior.

\section{A Teoria Semiótica}

Para Santaella (1994, p. 1), Semiótica é "algo nascendo e em processo de crescimento. Esse algo é uma ciência, um território do saber e do conhecimento ainda não sedimentado, indagações e investigações em progresso."

De maneira objetiva, Niemeyer (2003, p. 19) assinala que "Semiótica (do grego semeion = signo) é a teoria geral dos signos", sendo que "signo" "é algo que representa alguma coisa para alguém em determinada circunstância". Portanto, um signo está no lugar de algo, mas não é a própria coisa, porque é apenas um modo disso ser lembrado por alguém em certo contexto (NIEMEYER, 2003).

No contexto semiótico, signo é considerado como processo, sendo ao mesmo tempo causa e efeito da significação, ou seja, da associação entre o que é percebido e o que é relacionado a isso. Diante do mundo, o sujeito intérprete é levado a construir interpretações, e tais interpretações se organizam nas chamadas "semioses", como substituições associativas e operações de construção do sentido, que acontecem no pensamento. O objeto semiótico pode ser uma coisa, sensação ou acontecimento.

A noção de processo indica o signo como um conjunto dinâmico de três componentes: (1) a parte percebida, que é denominada "representamen"; (2) a parte referida, que é denominada "objeto", e (3) a parte que relaciona as outras duas, que é denominada "interpretante. A dinâmica entre as partes se apresenta como um desdobramento. "Signo é o processo mental das operações de substituição, a realização da representação, através do engenho e processamento cerebral, produzindo aquilo que se constitui no que chamamos de mente ou pensamento" (TURIN, 2007, p. 33).

Peirce propôs a estrutura do signo composta por três tricotomias;

1. A "primeira tricotomia" caracteriza os tipos de signo com relação ao "representâmen", podendo ser: "qualissigno"; "sinssigno", ou "legissigno", correspondendo "às dimensões sintáticas e materiais do produto" (NIEMEYER, 2003, p. 41).

2. A "segunda tricotomia" caracteriza os tipos de signo com relação ao "objeto", podendo ser: "ícone"; "índice", ou "símbolo", de acordo com "o modo como o signo se refere àquilo que ele representa" (NIEMEYER, 2003, p. 36), demarcando a dimensão semântica do signo. 
O signo icônico se caracteriza por relação de semelhança, entre o que é percebido e o que é representado. $O$ signo indicial ocorre por relação de contiguidade ou causa e efeito, entre o que é percebido e o que é representado. O signo simbólico decorre de uma convenção, que relaciona o que é percebido com o que é representado. Ícones, índices e símbolos não existem de maneira independente, porque são dimensões do processo de construção de um mesmo signo. Ao mesmo tempo, todo signo é ícone, porque é semelhante a alguma coisa; índice, porque é contíguo a alguma coisa, e símbolo, porque é convencionado como representante de alguma coisa. Todavia, as coisas com as quais o signo se relaciona como ícone, índice e símbolo não são necessariamente as mesmas.

3. A "terceira tricotomia" caracteriza as possibilidades interpretativas do signo e se estabelece com relação ao "interpretante", podendo ser: "rema"; "dicente", ou "argumento". Assim, "rema" representa um primeiro nível de impressões e dúvidas, decorrentes de um contato inicial com o novo. "Dicente" remete ao pensamento que constata a existência de algo independente da representação. "Argumento" é produto de afirmações interpretativas a respeito do observado, devido à aplicação de regras e certezas culturais a respeito do objeto em questão (NIEMEYER, 2003).

Peirce propôs três categorias fenomenológicas: (1) "primeiridade"; (2) "secundidade", e (3) "terceiridade". Concordando com Santaella (1994), considera-se que a primeiridade abriga as sensações e sentimentos como aspectos próprios do sujeito que percebe o signo, sendo motivadas por características estético-sintáticas do "representâmen", definindo sua iconicidade. A secundidade se estabelece através da relação de contiguidade entre o "representâmen" e o "objeto" do signo, indicando os aspectos do signo que se estabelecem externamente, com relação às sensações vivenciadas pelo sujeito. A terceiridade é determinada pelo acervo dos códigos culturais que estabelecem de maneira convencional as relações entre as sensações do sujeito (primeiridade) e as expressões da realidade externa (secundidade).

\section{Descrição e interpretação semiótica do novo logotipo "Uno"}

A respeito do logotipo da marca "Uno", considera-se que a relação entre o produto e sua marca gráfica é estabelecida por recorrência de aspectos formais. Isso diferencia o logotipo do novo "Uno" de outras marcas de veículos, que enfatizam a associação de valores simbólicos da cultura em geral aos produtos que representam. Além disso, corrobora a ideia que o design do novo modelo do automóvel "Uno" foi prioritariamente projetado para atender à necessidade de atualização estéticosimbólica de um produto que, historicamente, é um sucesso de mercado.

\section{Aspectos descritivos}

Houve uma reportagem da revista "Quatro Rodas", que foi veiculada na internet em maio de 2010, sobre o lançamento de produtos com o novo modelo "Uno". Trata-se de uma publicação comercial, mas com longa tradição e prestígio na área automobilística. Na reportagem, há a afirmação de que tudo é novo com relação ao modelo "Uno Mille". Pois, "em comum com o veterano popular, o Novo Uno tem apenas o nome. Trata-se de um projeto completamente novo" (QUATRO RODAS, 2010). O conceito adotado é publicitariamente resumido na expressão: "Novo Uno. Novo Tudo". Inclusive, há referências indicando mudanças em aspectos tecnológicos, relacionados ao desempenho do automóvel. Todavia, a ênfase da reportagem recai sobre os aspectos formais de seu design, reforçando que são a configuração externa ou interna e a visualidade que diferenciam totalmente o novo modelo com relação ao antigo. "Os traços retilíneos são a principal característica do Uno, sendo que a grade dianteira - sem efeito funcional, diga-se de passagem - traduz a tendência de estilo batizada pela Fiat como 'round square'" (QUATRO RODAS, 2010).

É facilmente percebida e também foi repetidamente citada a semelhança entre as formas adotadas no design do automóvel (Fig. 2 e 3) e as formas adotadas no design do logotipo de sua marca 
CAMPOS, Bruno; PERASSI, Richard

(Fig. 4). As formas definidoras do produto e do logotipo são os retângulos com ângulos arredondados. "As referências ao quadrado aparecem por todos os lados, desde o desenho das rodas da versão Attractive até o logotipo do carro, que reproduz o formato da grade frontal. Na traseira, as lanternas em posição elevada recorrem novamente ao tema 'quadrado arredondado'”' (QUATRO RODAS, 2010).

Figura 3 - O formato retangular arredondado nas formas do automóvel.

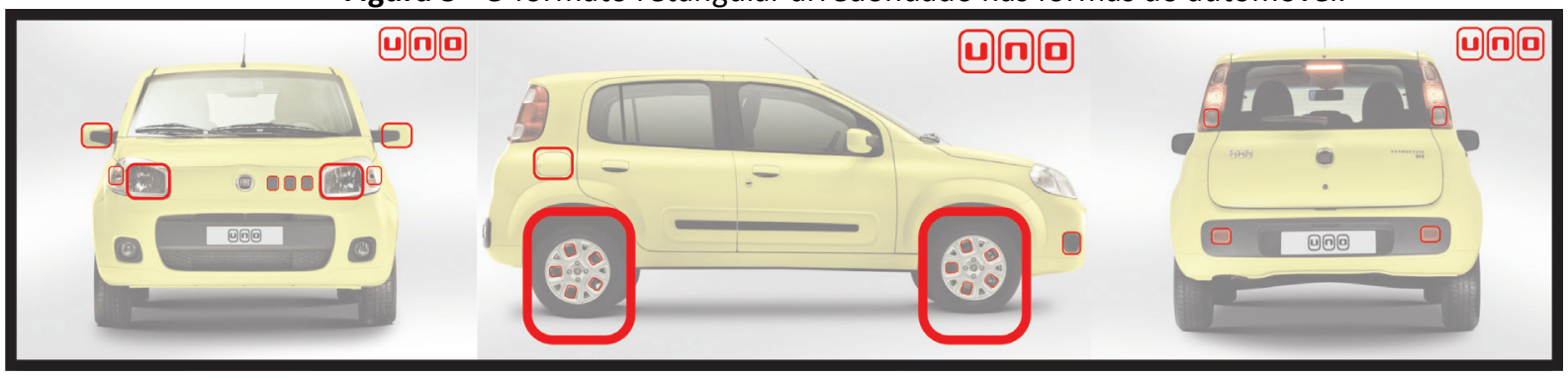

Fonte: adaptação do autor

Visualmente, portanto, há analogia ou relação icônica, que é determinada na semelhança entre formas recorrentes na aparência do automóvel (Fig. 2 e 4) e nas formas que configuram o logotipo (Fig. 4).

Figura 4 - Logotipo do Novo Fiat Uno

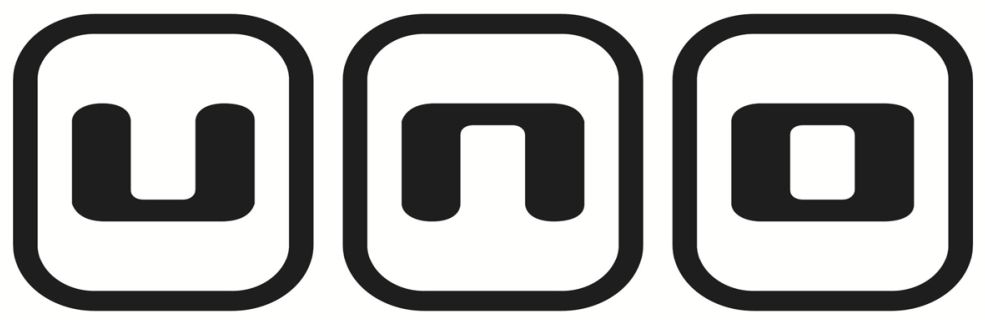

Fonte: vetorização do autor.

No logotipo da marca, compondo o nome "uno", as letras são circunscritas por três formas retangulares vazadas, com ângulos arredondados e linhas largas. Cada uma das letras do nome aparece no interior de uma das formas vazadas. A fonte tipográfica apresenta traços largos e sem serifas.

A configuração das três letras segue uma rígida matriz gráfica, que é completamente expressa na letra "O". Portanto, as letras " $U$ " e " $\mathrm{N}$ " são compostas de acordo com estrutura padronizada, sendo que essas duas letras repetem o mesmo desenho em posição invertida. A sobreposição das duas primeiras letras, " $U$ " e " $N$ ", recompõe a matriz expressa na letra final "O".

O logotipo também é apresentado em outras versões, com tratamentos gráficos diferenciados, havendo versões que simulam tridimensionalidade e tratamentos, sugerindo as formas e as letras modeladas em materiais como acrílico ou metal (Fig. 5).

Figura 5 - Representação tridimensional do logotipo da marca "Uno".

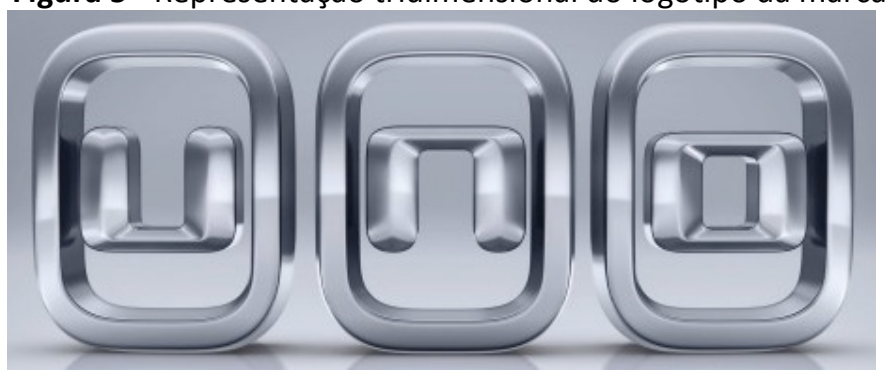

Fonte: Sítio Auto Foz Veículos (2011) 
Na prática de marcação dos produtos da marca, o logotipo pode ser moldado em metal (Fig. 6), plástico ou outros materiais e aplicado em diferentes partes do veículo ou de outros produtos relacionados ao automóvel.

Figura 6 - Aplicações do logotipo tridimensional da marca "Uno" na superfície externa de automóveis.
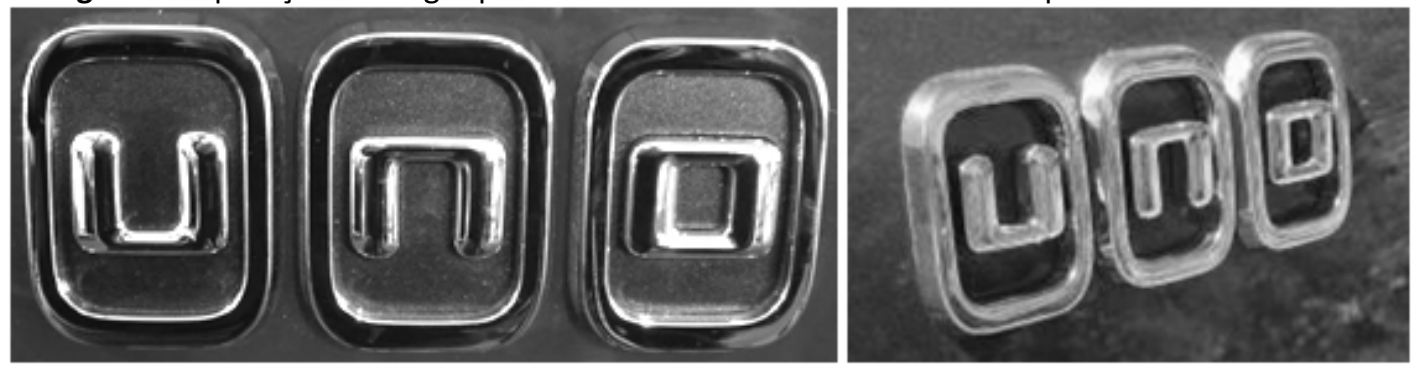

Fonte: Imagens fotográficas produzidas pelo autor.

Oficialmente, como foi consagrado na tradição de marcação de automóveis, o logotipo é apresentado na parte traseira do automóvel, do lado esquerdo de quem observa o produto.

\section{Aspectos interpretativos}

É interessante a comparação entre a imagem lateral do modelo antigo do automóvel e do modelo novo do automóvel, porque ambos são identificados com marca "Uno" (Fig. 7). No âmbito da categoria de "primeiridade", proposta pela teoria Semiótica como foi descrita anteriormente, a visão do modelo antigo promove sensações que sugerem um veículo mais leve e transparente, mais frágil, mais amplo, com certa inclinação para frente, sugerindo também rapidez. Por sua vez, também no âmbito da "primeiridade", relacionando sensações e sentimentos, a visão do modelo novo promove sensações que sugerem um veículo mais forte e robusto, mais pesado e compacto, bem postado sobre as quatro rodas e mais aderente ao solo. Assim, as qualidades visuais do modelo antigo sugerem leveza, amplitude, fragilidade e rapidez, enquanto as qualidades visuais do modelo novo sugerem força, robustez, opacidade, estabilidade e segurança.

Figura 7 - Imagens laterais de modelos da marca "Uno".

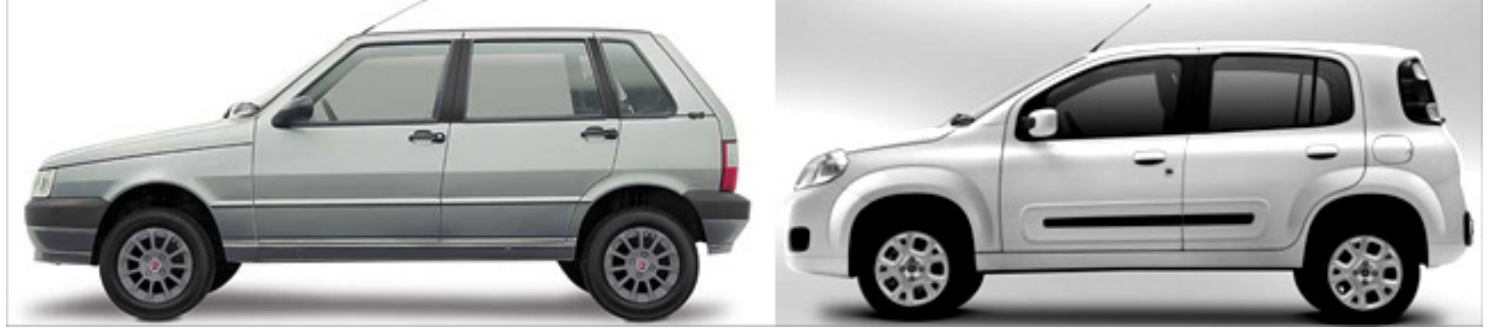

Fonte: adaptação do autor.

Os logotipos da marca em cada um dos modelos apresentados mantêm uma relação icônica com as formas dos automóveis que identificam e qualificam (Fig. 8). Assim, com relação a sensações e sentimentos no âmbito da categoria semiótica de "primeiridade", a imagem do logotipo "Uno Mille" sugere rapidez e leveza. A sensação de rapidez decorre da inclinação de suas formas e a sensação de leveza é sugerida pelo fino contorno que desenha a tipografia das palavras, especialmente, da palavra "Mille" (Fig. 8).

Por sua vez, a imagem do logotipo "Uno" sugere estabilidade, força e segurança. A sensação de estabilidade decorre da ortogonalidade das formas, que se mostram perfeitamente paralelas e perpendiculares em todas as direções. A sensação de estabilidade aliada à percepção das linhas largas das letras e das formas que as circunscrevem sugerem força. A sensação de segurança é decorrente das sensações de estabilidade e força associadas à sensação de proteção sugerida pela situação das 
letras abrigadas pelas formas que as circunscrevem (Fig. 8).

Figura 8 - Imagens dos logotipos dos modelos da marca "Uno".

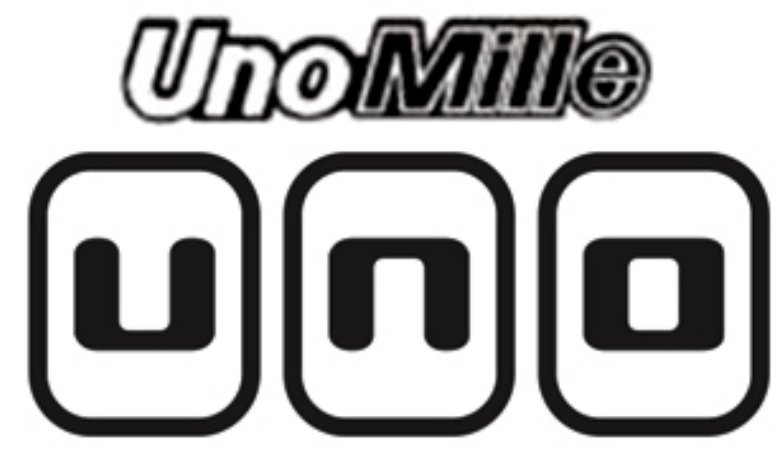

Fonte: adaptação do autor.

Do modo geral, a cultura como o campo das significações já estabeleceu relações básicas para todos os elementos que foram percebidos ao longo da história. Algumas dessas relações permanecem restritas aos acervos de culturas específicas. Mas, depois da consolidação da cultura de consumo, através da comunicação de massa, há um vasto acervo de associações de amplitude global, que participa do repertório comum do público consumidor. Assim, mesmo considerando que o novo modelo da marca "Uno" seja decorrente de um projeto único, que foi lançado como legitima novidade junto ao público, a cultura de consumo e a cultura em geral oferecem recursos para a categorização simbólica do automóvel, de acordo com parâmetros já existentes.

$\mathrm{Na}$ teoria Semiótica, as associações ou convenções culturais configuram a categoria fenomenológica da "terceiridade". Por exemplo, essas associações permitem ao observador identificar alguns rabiscos feitos com caneta sobre papel, primeiramente, como desenho, figura ou palavra e, em seguida, como representação de um objeto ou de um ser vivo. Contudo, materialmente, no âmbito da "secundidade", o desenho é apenas um conjunto de restos de tinta depositados pelo uso da caneta sobre uma folha de papel.

Na reportagem já citada (QUATRO RODAS, 2010), considera-se que "o desenho de linhas modernas e irreverentes (do novo automóvel da marca 'Uno') lembra a fórmula do Kia Soul, classificado pela montadora sul-coreana como 'carro-design'"' ${ }^{1}$. Do mesmo modo, é possível considerar que, pela ausência de um certo tipo de formalidade e de certos aspectos ou de elementos indicativos de luxo, ambos os modelos de automóveis apresentados e associados à marca "Uno" (Fig. 7), além de serem símbolos das marcas "Uno" e "Fiat", também, são símbolos de automóveis populares, com algum valor agregado, por detalhes que sugerem esportividade.

A sugestão de esportividade aparece mais claramente nas rodas do modelo antigo, como é apresentado na imagem anterior (Fig. 7), apesar do estilo geral do automóvel ser mais coerentemente categorizado como "carro popular de passeio". Todavia, no modelo novo (Fig. 7), todo o desenho do automóvel sugere um tipo de esportividade. O caráter esportivo, entretanto, não é relacionado aos esportes de velocidade, porque propõe sutis relações com esportes de força e resistência, que são denominados como "radicais". O automóvel é apresentado como um carro popular de passeio, cujas linhas lembram os automóveis do tipo "fora de estrada". Isso ocorre, especialmente, porque a parte abaixo da linha dos vidros do automóvel é mais larga ou maior que a parte de cima, reforçando a sensação de peso e de estabilidade.

Por analogia icônica, o logotipo da marca associado ao novo modelo do produto (Fig. 4 e 8), além de ser símbolo do automóvel e da marca "Fiat", também simboliza estabilidade, força e segurança. Mas, não sugere leveza e velocidade, simbolizando performances que requerem força, proteção e determinação. $O$ conjunto sequencial de três peças retangulares com ângulos arredondados, que circunscrevem as letras do nome, propõe associações com elos de correntes ou partes mecânicas de uma esteira rolante, como as que impulsionam alguns tipos de tratores e outras máquinas automotivas. 
Há relações icônicas no processo de associação entre o "representamen" do signo e o seu "objeto" que, neste caso, relaciona o logotipo "Uno" com o novo automóvel representado pela marca. Assim, além de ser um signo convencionado, o símbolo gráfico da marca "Uno" pode ser associado ao objeto representado, que é o automóvel, também, por relação icônica ou semelhança visual. Isso possibilita a identidade entre os sentidos expressos pela configuração do logotipo e pela configuração do automóvel, reiterando os valores simbólicos do produto.

Em outras situações, percebe-se relações diferentes, porque são metafóricas e, portanto, não icônicas. Por exemplo, no centro do brasão da marca "Ferrari” (Fig. 9), há a imagem de um cavalo preto em posição de salto.

Figura 9 - Brasão e logotipo da marca "Ferrari" de automóveis.

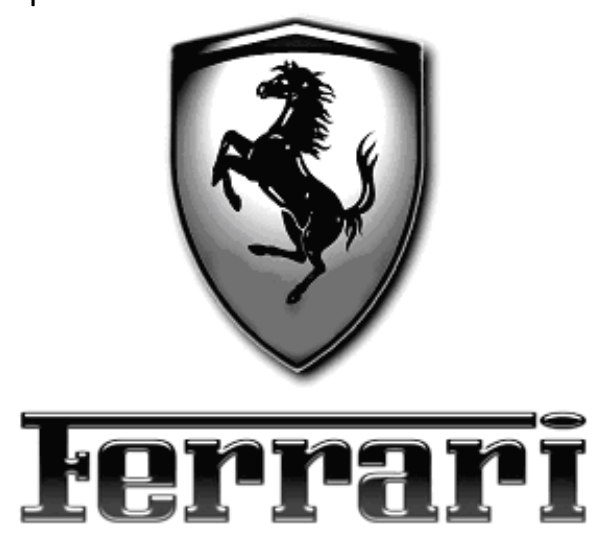

Fonte: Blog Raphael Freire (2011)

Os "objetos" representados por esse signo, também, são automóveis e não são cavalos. Portanto, não há uma relação de semelhança, icônica ou analógica entre o "objeto" representado no logotipo da marca, que é o cavalo, e o "objeto" representado pela marca, que é o carro. Todavia, o desenho no centro do brasão representa um cavalo que, devido a aspectos específicos de sua configuração, sugere agilidade, sofisticação e elegância, indicando os valores marcantes que são atribuídos também aos automóveis representados.

\section{Considerações Finais}

As montadoras promovem mudanças em seus automóveis, demarcando anualmente o lançamento de novas versões de seus produtos. Às vezes, essas mudanças são parcimoniosas e, outra vezes, são mais radicais, alterando parcialmente o conceito do produto. Inclusive, há momentos em que certas marcas de automóveis são retiradas de linha e substituídas por outras marcas e modelos.

A mudança radical dos produtos e do logotipo da marca "Uno", entretanto, caracteriza um caso interessante. Pois, praticamente, foi criada uma nova linha de produtos. Mas, com a clara intenção de manutenção da marca. Isso é justificado pelo sucesso alcançado pela marca no mercado de carros populares. Um sucesso devido à relação custo-benefício, considerando-se as qualidades dos automóveis e os preços acessíveis, que foram oferecidos ao público consumidor.

De acordo com as considerações a respeito do novo modelo e de suas versões e, também, considerando-se a expressão publicitária adotada: "novo Uno. Novo Tudo", percebe-se o investimento feito na renovação dos produtos, especialmente, na sua reconfiguração visual. Porém, percebe-se; também, a intenção de garantir a permanência da marca.

Os produtos e o logotipo da marca foram mudados. Mas, mantiveram-se o nome da marca e o seu posicionamento. Além disso, pelo menos temporariamente, foram mantidas as versões do produto anteriormente consagrado, com a marca "Mille". A palavra italiana "mille" é equivalente à palavra "mil" em língua portuguesa e servia para adjetivar antigas versões de mil cilindradas dos carros da marca "Uno". 
Houve, portanto, a intenção de manter os produtos anteriores, com um nome historicamente associado à marca "Uno", convivendo em paralelo ao lançamento e ao início das vendas da nova linha de produtos "Uno". Isso evidencia a previsão dos riscos envolvidos nas mudanças promovidas. Mas, também, indica que há a necessidade de mudança. Diante do sucesso da marca, a mudança mostrouse temerária. Assim, as mudanças promovidas permitem pensar que foram prioritariamente motivadas pelo obsolescência estético-simbólica dos produtos e do posicionamento da marca "Uno".

As mudanças foram promovidas para atualizar os aspectos simbólicos da marca, procurando garantir e estender a longevidade de seu sucesso no mercado, sem abandonar imediatamente a formulação que promoveu o êxito da marca até o presente momento.

A perspectiva proposta aponta um conjunto de questões semióticas, nas mudanças promovidas nos produtos e no posicionamento da marca "Uno". O automóvel no modelo antigo (fig. 1 e 7) é símbolo de tradição, modernismo e sucesso, expressando os seguintes valores: racionalidade no projeto, rapidez e leveza no desempenho, como carro de passeio popular que pode ser apresentado com detalhes esportivos. O automóvel no modelo novo (Fig. 2 e 7) é símbolo de inovação, pósmodernismo e ousadia, expressando os seguintes valores: passionalidade no projeto, estabilidade, força e segurança, como carro de passeio popular com linhas esportivas associadas aos esportes do tipo "fora de estrada".

Em parte, a simbologia dos modelos, que se estabelece na categoriaSemiótica de "terceiridade", porque depende das convenções culturais, não se confirma no âmbito da "secundidade", mas são motivadas por sensações e sentimentos, que caracterizam o âmbito da "primeiridade". Os automóveis do modelo antigo (Fig. 1 e 7) foram considerados em relação de contiguidade, que é característica da "secundidade", com aspectos que indicam leveza e agilidade. Pois, sua direção leve e seu tamanho reduzido, permitem desembaraço e rapidez de deslocamento nos espaços urbanos. Todavia, a relação entre força e esportividade radical, que é proposta na visualidade dos automóveis do modelo novo (Fig. 2 e 7), provavelmente, não será confirmada na prática, caracterizando-se como efeito típico de "primeiridade".

O desenho do logotipo em estudo (fig. 4) é um símbolo convencionado da marca e das novas versões de seus automóveis, caracterizando-se como "legi-signo", devido a sua relação simbólicoconvencional e arbitrária com seu objeto. Assim, promove no nível simbólico de "terceiridade" um interpretante do tipo "argumento". Todavia, a visualidade das formas do logotipo estabelece analogias com as formas dos automóveis os quais representa. Isso motiva a associação entre o símbolo e os produtos que representa, qualificando a convenção com aspectos analógicos ou de semelhança. Sob essa relação icônica com seu objeto, o logotipo em estudo é caracterizado como "qualissigno" que, no âmbito da categoria semiótica de "primeiridade", promovendo sensações e sentimentos, que reforçam as sugestões de estabilidade, força e segurança, entre outras. Assim, a visão das formas do logotipo promove no nível da estético de "primeiridade" um interpretante do tipo "remático".

Há, portanto, uma dupla estratégia de representação, na relação entre o logotipo em estudo (Fig. 4) e os automóveis que representa (Fig. 2 e 7). No nível lógico de "terceiridade", o logotipo é convencionalmente e publicitariamente relacionado ao nome "Uno" e aos novos automóveis da marca, estabelecendo a relação simbólico-arbitrária por convenção cultural. No nível analógico ou estético de "primeiridade", há associação por semelhança de sensações entre a visualidade do logotipo e a visualidade do automóveis representados, determinando um aspecto motivador e propondo um interpretante remático, que reforça analogicamente a relação arbitrada entre o logotipo e os produtos que essa representa.

\section{Notas}

${ }^{1}$ Kia Soul é a marca de um automóvel da empresa sul-coreana "Kia Motors", cuja representação brasileira é identificada como"Kia Motors do Brasil". 
Estratégia de representação em projeto de logotipia: Leitura semiótica da marca gráfica UNO/FIAT

\section{Referências}

ALVES, M.; ARRUDA, S. Como elaborar um Artigo Científico. UFSC - Universidade Federal de Santa Catarina. Disponível em [http://www.bu.ufsc.br/design/ArtigoCientifico.pdf] acessado em $10 \mathrm{de}$ setembro de 2011.

NIEMEYER, Lucy. Elementos de semiótica aplicados ao design. Rio de Janeiro: 2AB, 2003. 78 p.

NOVO UNO 2012. In: FIAT. Disponível em http://www.fiat.com.br/monte-seu-carro/conheca/195/ NOVO+UNO+2012/. Acessado em 22 de setembro de 2011.

QUATRO RODAS. O novo Fiat Uno. In: Revista digital Quatro Rodas. Disponível em http://quatrorodas. abril.com.br/carros/lancamentos/novo-fiat-uno-556006.shtml. Acessado em 10 de outubro de 2011.

SANTAELLA, Lucia. O que e semiotica. 12. ed. São Paulo: Brasiliense, 1994. 84 p. (Primeiros passos).

The Fiat Brand. Disponível em http://www.fiat.com/cgi-bin/pbrand.dll/FIAT_COM/fbrand/fbrand. jsp?BV_SessionID=@@@@0495276657.1319646262@@@@\&B_EngineID=cccdadfelmgjfkecefecejg dfkhdfjh.0. Acessado em 21 de setembro de 2011.

TURIN, Roti Mielba. Aulas: introdução ao estudo das linguagens. São Paolo: Annablume, 2007, 106 p. 